ISTIGHNA, Vol. 3, No 1, Januari 2020 P-ISSN 1979-2824 E-ISSN 2655-8459

Homepage: http://e-journal.stit-islamic-village.ac.id/index.php/istighna

Burhanudin, Ari Prayoga, Irawan

Manajemen Peningkatan Mutu Pendidikan di Sekolah Islam

\title{
MANAJEMEN PENINGKATAN MUTU PENDIDIKAN DI SEKOLAH ISLAM
}

\author{
Burhanudin \\ burhanudinstw@gmail.com \\ Program Pascasarjana UIN Sunan Gunung Djati Bandung \\ Ari Prayoga \\ ariprayoga@madrasah.id \\ Program Pascasarjana UIN Sunan Gunung Djati Bandung \\ Irawan \\ irawan@uinsgd.ac.id \\ Perkumpulan Sarjana Manajemen Pendidikan Islam (PERSMAPI) Indonesia
}

\begin{abstract}
This study aims to uncover the quality improvement planning, quality improvement control, quality improvement, and the results of improving the quality improvement of SMP Plus Al-Aqsa Sumedang. This study uses the Juran trilogy theory including; planning, controlling and improving the quality of education. The approach used in this research is qualitative with descriptive methods. Data collection techniques used include; observation, interview, and documentation study. The results of the study show that; first, the quality planning carried out at SMP Plus Al-Aqsa namely; the strategic step of analyzing market share needs, formulating the vision, mission, and goals of the institution. Second, quality control is implemented at SMP Plus Al-Aqsa namely; the determination of the work structure and supervision carried out by the principal and the internal quality team. Third, quality improvements carried out at Al-Aqsa Plus Junior High School namely; improvement of infrastructure to support institutional activities, formulate short-term, medium-term, long-term programs, and evaluate and identify specific areas that need improvement. The results of improving quality at SMP Plus Al-Aqsa have an impact on learning processes that are more innovative, student achievement and school achievement, customer satisfaction both internally and externally, and compliance with eight national education standards.
\end{abstract}

\section{Keyword: Management, Quality Improvement, SMP Plus}

\begin{abstract}
Abstrak: Penelitian ini bertujuan untuk mengungkap perencanaan peningkatan mutu, pengendalian peningkatan mutu, perbaikan peningkatan mutu, dan hasil perbaikan peningkatan mutu Sekolah Menengah Pertama Plus Al-Aqsha Sumedang. Penelitian ini menggunakan teori trilogi Juran meliputi; perencanaan, pengendalian, dan perbaikan mutu pendidikan. Pendekatan yang digunakan pada penelitian ini yaitu kualitatif dengan metode deskriptif. Teknik pengumpulan data yang digunakan meliputi; observasi, wawancara, dan studi dokumentasi. Hasil dari penelitian menunjukan bahwa; pertama, perencanaan mutu yang dilaksanakan di SMP Plus Al-Aqsha yaitu; langkah strategis analisis kebutuhan pangsa pasar, merumuskan visi, misi dan tujuan lembaga. Kedua, pengendalian mutu yang dilaksanakan di SMP Plus Al-Aqsha yaitu; penentuan struktur kerja serta pengawasan yang dilakukan oleh kepala sekolah dan tim internal mutu. Ketiga, perbaikan mutu yang
\end{abstract}

Peer reviewed under reponsibility of STIT ISLAMIC VILLAGE.

(c) 2018 STIT ISLAMIC VILLAGE, All right reserved, This is an open access article under 53

the CC BY SA license (https://creativecommons.org/licenses/by-sa/4.0/) 
ISTIGHNA, Vol. 3, No 1, Januari 2020 P-ISSN 1979-2824 E-ISSN 2655-8459

Homepage: http://e-journal.stit-islamic-village.ac.id/index.php/istighna

Burhanudin, Ari Prayoga, Irawan

Manajemen Peningkatan Mutu Pendidikan di Sekolah Islam

dilaksanakan pada SMP Plus Al-Aqsha yaitu; perbaikan sarana prasarana penunjang kegiatan lembaga, merumuskan program jangka pendek, jangka menengah, jangka panjang, dan evaluasi serta mengidentifikasi area tertentu yang membutuhkan perbaikan. Hasil dari pada peningkatan mutu pada SMP Plus Al-Aqsha memiliki dampak terhadap proses pembelajaran yang lebih inovatif, prestasi siswa dan pencapaian sekolah, kepuasan pelanggan baik internal maupun eksternal, serta pemenuhan delapan standar pendidikan nasional.

Kata Kunci: Manajemen; peningkatan mutu; SMP Plus

\section{A. PENDAHULUAN}

Lembaga pendidikan sebagai pencetak generasi bangsa harus mampu menghadirkan sesuatu yang menjual kualitas agar lulusan yang dihasilkan mampu memiliki keunggulan-keunggulan yang akan menopang kehidupan bangsa kedepanya. Berdasarkan hasil dari research pengendalian mutu pendidikan, ternyata pendidikan memiliki peranan yang penting dalam mengembangkan sumber daya manusia dan individu berkualitas ${ }^{1}$. Majunya lembaga organisasi pendidikan sangat dituntut dengan adanya arus kompetisi antar sesama lembaga pendidikan. Kemampuan dalam persaingan tersebut menjadi salah satu kesuksesan lembaga organisasi pendidikan di Indonesia. Persaingan ini akan mengakibatkan pihak lembaga sekolah memiliki keinginan melaksanakan peningkatan mutu pendidikan sebagai salah satu cara untuk meningkatkan kompetisi dengan sekolah lain ${ }^{2}$.

Dalam amanat Undang-Undang Nomor 20 Tahun 2003 Tentang Sistem Pendidikan Nasional, Lembaga pendidikan yang unggul dan memiliki mutu minimalnya memenuhi 8 standar Nasional pendidikan di Indonesia yaitu: Standar Kompetensi Lulusan, Standar isi, Standar pendidik dan Tenaga Kependidikan, Standar Sarana dan Prasarana, Pengelolaan pendidikan, Pembiayaan pendidikan dan Standar penilaian pendidikan ${ }^{3}$.

Mutu pendidikan tak hanya ditentukan oleh lembaga sekolah sebagai organisasi pengajaran akan tetapi juga disesuaikan dengan apa yang menjadi harapan costemer atau masyarakat yang memiliki kecenderungan selalu berkembang secara cepat seiring dengan kemajuan dan tuntutan zaman. Mengacu pada kecenderungan tersebut, penilaian

\footnotetext{
${ }^{1}$ Nana Syaodih, Pengendalian Mutu Pendidikan Sekolah Menengah, I (Bandung: Refika Aditama, 2006).

${ }^{2}$ Ari Prayoga and others, 'Implementasi Penjaminan Mutu Madrasah', Muróbbî: Jurnal Ilmu Pendidikan, 3.1 (2019), 70-84 <http://jurnal.iaibafa.ac.id/index.php/murobbi/article /view/183>.

${ }^{3}$ UU SISDIKNAS RI., Undang-Undang Republik Indonesia Nomor 20 Tahun 2003 Tentang Sistem Pendidikan Nasional (Jakarta, 2003).
} 
ISTIGHNA, Vol. 3, No 1, Januari 2020 P-ISSN 1979-2824 E-ISSN 2655-8459

Homepage: http://e-journal.stit-islamic-village.ac.id/index.php/istighna

Burhanudin, Ari Prayoga, Irawan

Manajemen Peningkatan Mutu Pendidikan di Sekolah Islam

masyarakat mengenai mutu lulusan lembaga sekolah pun terjadi perberkembangan. Oleh karena itu sekolah perlu secara terus menerus meningkatkan mutu lulusan luarannya melalui penyesuaian dengan perkembangan tuntutan Customs masyarakat menuju pada mutu pendidikan yang dilandasi tolak ukur norma ideal ${ }^{4}$.

Dari fenomena di atas dapat terlihat bahwa peningkatan mutu sekolah sangat penting untuk perubahan di sekolah. Inovasi-inovasi yang dibuat dalam pengembangan mutu sekolah di SMP Plus Al-Aqsha perlu diteliti dan dikembangkan secara berkelanjutan.

\section{B. METODE PENELITIAN}

Pendekatan Penelitian yang digunakan dalam penelitian ini adalah pendekatan kualitatif metode deskriptif yaitu prosedur pemecahan masalah diselidiki dengan menggambarkan keadaan objek penelitian pada saat sekarang berdasarkan fakta - fakta atau apa adanya ${ }^{5}$. Sumber data meliputi fenomena, kata-kata tertulis, lisan dari orang-orang, gejala-gejala, kejadian dan peristiwa yang dapat diamati yang berkaitan dengan manajemen peningkatan mutu ${ }^{6}$. Teknik sampling yang digunakan, yaitu dengan mewawancarai wakil kepala sekolah sebagai key informan, kemudian diikuti oleh snowball Process kepala sekolah bidang kurikulum, sarana prasarana, pendidik. Lokasi penelitian di Sekolah Menengah Pertama Plus Al-Aqsha Sumedang.

Teknik pengumpulan data menggunakan; observasi partisipatif kegiatan pembinaan di setiap ekstrakurikuler, wawancara terstruktur dilakukan bersama kepala sekolah wakil kepala bidang kesiswaan, dan tim penjamin mutu internal tentang perencanaan, pengendalian dan perbaikan mutu di SMP Plus Al-Aqsha ${ }^{7}$. Teknik analisis data yang digunakan adalah teknik analisis data deskriptif kualitatif model interaktif meliputi ${ }^{8}$; unitisasi data, kategorisasi data, reduksi data, kodifikasi data, penelaahan data dan penafsiran data. Uji keabsahan data melalui derajat kepercayaan (credibility),

4 Syaiful Sagala, Konsep Dan Makna Belajaran Untuk Membantu Memecahkan Problematika Belajar Dan Mengajar, II (Bandung: Alfabeta, 2010).

${ }^{5}$ Lexy J. Moleong, Metode Penelitian Kualitatif (Bandung: Remaja Rosdakarya, 2004).

6 Philip Buckley and Irawan Irawan, 'The Scientific Paradigm of Islamic Education Management: Phenomenology Perspective', Jurnal Pendidikan Islam, 2.1 (2015), 1-29 $<$ https://doi.org/10.15575/jpi.v2i1.701>.

7 Sugiyono, Metode Penelitian Kuantitatif, Kualitatif Dan R\&D, 24th edn (Bandung: Alfabeta, 2016).

${ }^{8}$ M. B. Miles and A. M. Huberman, Qualitative Data Analysis, Second Edi (London: SAGE Publications, Inc., 1994). 
ISTIGHNA, Vol. 3, No 1, Januari 2020 P-ISSN 1979-2824 E-ISSN 2655-8459

Homepage: http://e-journal.stit-islamic-village.ac.id/index.php/istighna

Burhanudin, Ari Prayoga, Irawan

Manajemen Peningkatan Mutu Pendidikan di Sekolah Islam

keteralihan (transferability), kebergantungan (dependability), dan kepastian (confirmability).

\section{HASIL DAN PEMBAHASAN}

\section{Perencanaan Peningkatan Mutu}

Perencanaan merupakan hal pertama yang dilakukan dalam langkah peningkatan mutu, sehingga dalam langkah awal ini kepala sekolah selaku perumus perencanaan melakukan pemetaan berkaitan dengan kebutuhan masyarakat sekitar serta regulasi atau ketentuan yang dibuat pemerintah sehingga ketika merumuskan perencanaan memiliki kesesuaian dengan kebutuhan masyarakat dan tujuan pemerintah dalam menyelenggarakan pendidikan. Perencanaan Mutu (Quality Planning) merupakan tahapan perencanaan tentang mutu yang diinginkan dari suatu produk atau pelayanan. Pada tahapn ini dilakukan fokus pada penyusunan kebijakan mutu, tujuan mutu dan proses operasional untuk mencapai tujuan ${ }^{9}$.

Abdullas syafe'i bergerak sebagai pimpinan penelitian pengembangan lembaga yang menganalisis kebutuhan pasar sekolah. 2 tahun berturut-turut sekolah mengalami kemunduran dalam penerimaan siswa baru, setelah melakukan analisis permasalahan ternyata ada kebutuhan pasar yang tidak terpenuhi yaitu program tahfiz al-quran, sehingga ditemukan bahwa kebutuhan pasar saat ini adalah tahfiz al-quran. Tahun berikutnya sekolah membuat program baru yang berkaitan dengan tahfiz al-quran.

Target pemasaran sekolah ini adalah Nasional karena ada siswa yang bersekolah di Jatinangor dari luar pulau Jawa seperti Sumatra, Kalimantan. Pada tahun 2014 ada siswa yang bersekolah dari Madinah sehingga. Secara keseluruhan sekolah menargetkan pada tingkat nasional untuk pangsa pasarnya. Dalam pemasaranya sekolah bekerja sama dengan siswa yaitu dengan teknis setiap siswa diberi brosur sekolah kemudian diteruskan pada keluarga terdekatnya, kemudian cara yang kedua yaitu promosi melalui laman website resmi sekolah serta iklan di pamflet ${ }^{10}$.

Berdasarkan visi dan misi nasional, pendidikan nasional bertujuan untuk mengembangkan potensi peserta didik agar menjadi manusia yang bertakwa kepada Tuhan

${ }^{9}$ Uhar Suharsaputra, Administrasi Pendidikan (Bandung: PT. Rafika Aditama, 2014).

${ }^{10}$ Kepala Sekolah, CL.2.KS.W.PM. Wawancara Terstruktur Data Kelembagaan Sekolah (Sumedang, 2019). 
ISTIGHNA, Vol. 3, No 1, Januari 2020 P-ISSN 1979-2824 E-ISSN 2655-8459

Homepage: http://e-journal.stit-islamic-village.ac.id/index.php/istighna

Burhanudin, Ari Prayoga, Irawan

Manajemen Peningkatan Mutu Pendidikan di Sekolah Islam

yang maha esa, berakhlak mulia, sehat, berilmu, cakap, kreatif, mandiri dan menjadi warga negara yang demokratis serta bertanggung jawab.

Mengacu pada visi dan misi serta tujuan pendidikan nasional diatas, maka Visi; menjadikan sekolah unggul kompetitif dan islami, Misi; a) menyelenggarakan pendidikan secara profesional, didukung oleh manajemen lembaga secara efektif dan efisien berdasarkan manajemen modern dan nilai-nilai spiritual islam; b) meningkatkan kualitas fasilitas dan proses pembelajaran untuk mencapai standar mutu lulusan yang unggul dan kompetitif; c) membimbing dan memfasilitasi peserta didik untuk mandiri, berpikir kreatif, berbudi tinggi dan berbadan sehat; d) membangun budaya mutu, etos kerja, dan disiplin seluruh sivitas akademik; e) membangun ukhuwah islamiyyah, akhlak mulia dan budaya ilmiah; f) membangun kerjasama dalam pengembangan lembaga dan pendidik, baik dengan pihak dalam maupun luar.

Tujuan pendidikan di SMP Plus Al-Aqsha meliputi; a) mendidik dan memfasilitasi peserta didik agar berbudi tinggi, berbadan sehat, berpengetahuan luas, dan berpikir kreatif dan dinamis; b) mempersiapkan peserta didik agar memiliki jiwa keikhlasan, kesederhanaan, kemandirian, kekeluargaan, kebebasan; c) mempersiapkan peserta didik untuk menjadi anggota masyarakat yang siap pakai dan siap guna; d) mempersiapkan peserta didik untuk memiliki berbagai kompetensi dan motivasi dalam melanjutkan pendidikan ke jenjang yang lebih tinggi ${ }^{11}$.

\section{Pengendalian Peningkatan Mutu}

Pengendalian mutu yang dilakukan SMP Plus Al-Aqsha menggunakan berkaitan dengan proses memastikan semua perencanaan dapat terlaksana dan berjalan dengan baik dan benar, langkah yang dilakukan kepala sekolah dalam pengendalian mutu meliputi:

a. Penentuan struktur kerja

Dalam penentuan struktur kerja kepala sekolah mengacu pada ketentuan dinas pendidikan. Kepala sekolah sebagai pemegang kebijakan, wakil kepala sekolah bidang kurikulum, wakil kepala sekolah bidang kesiswaan dan wakil kepala sekolah bidang sarana prasarana ${ }^{12}$. Penentuan struktur kerja berpedoman pada kompetensi dan

${ }^{11}$ Kepala Sekolah Bidang Kurikulum, Dokumen 1 Sekolah Menengah Pertama Plus AlAqsha Sumedang (Sumedang, 2019).

${ }^{12}$ Ari Prayoga, Rismaya Muharomah, and Sutarti Sutarti, 'Implementasi Kepemimpinan Transformatif Kepala Madrasah Aliyah Ma'arif Cilageni Kadungora', Attaqwa: Jurnal Ilmu Pendidikan Islam, 15.01 (2019), 33-44 <https://doi.org/10.5281/zenodo.3375534>. 
ISTIGHNA, Vol. 3, No 1, Januari 2020 P-ISSN 1979-2824 E-ISSN 2655-8459

Homepage: http://e-journal.stit-islamic-village.ac.id/index.php/istighna

Burhanudin, Ari Prayoga, Irawan

Manajemen Peningkatan Mutu Pendidikan di Sekolah Islam

kualifikasi jabatan individu tersebut. SMP Al-Aqsha mempunyai dua struktur kepengurusan yaitu struktur kepengurusan Sekolah dan juga struktur kepengurusan Pesantren. Untuk kepengurusan pesantren mengikuti struktur yang digunakan pesantren pada umumnya.

b. Pengawasan

Pengawasan yang dilakukan SMP Plus Al-Aqsha dilakukan dengan internal Control menggunkan tiga cara pertama dilakukan dengan menunjuk tim khusus yaitu SPI (Satuan Pengawas Internal) dimana SPI ini mengawasi semua kegiatan dan pegawai sekolah termasuk kepala sekolah. Pengelolaan SPI dilakukan oleh Iman dan Yanti. Kedua pengawasan secara tidak langsung dengan media elektronik. Pada setiap raung kelas di pasang kamera CCTV sehingga tenaga pengajar yang telat atau tidak masuk kelas dapat terpantau. Selain itu pengawasan secara tidak langsung dengan media elektronik yang lainya adalah absensi melalui mesin fingerprint dan secara manual. Tindak lanjut atas keterlambatan tenaga pendidikan diberikan hukuman pemotongan honorarium transportasi.

Sejalan dengan implementasi pengawasan internal di SMP Al-Aqsha menurut Hasibuan dalam Badrudin mengemukakan empat macam pengendalian yaitu ${ }^{13}$ :

a. Internal Control (pengendalian internal) adalah pengendalian yang dilaksanakan oleh seorang atasan terhadap bawahanya. Cakupan dari pengendalian tersebut meliputi hal yang sangat luas, baik dari segi pelaksanaan tugas, prosedural kerja, kedisiplinan pegawai. Audit control yaitu pemeriksaan atau penilaian atas permasalahan yang berkaitan dengan pendokumentasian organisasi. Pengendalian atas permasalahan khusus, yaitu tentang kebenaran pembukuan suatu lembaga.

b. Ekternal control (pengendalian eksternal) yaitu pengendalian yang dilaksanakan oleh pihak luar organisasi. Pengendalian tersebut bisa dilaksanakan baik secara formal ataupun informal, contohnya pemeriksaan pembukuan oleh pihak kantor akuntan serta penilaian yang dilaksanakan oleh masyarakat akan sangat berbeda hasilnya.

c. Formal contol (pengendalian resmi) yaitu pemeriksaan yang dilakukan oleh instansi atau pejabat resmi dan dapat dilakukan secara intern ataupun ekstern. Misalnya pemeriksaan yang dilakukan Badan Pemeriksa Keuangan.

${ }^{13}$ Badrudin, Dasar-Dasar Manajemen (Bandung: Al-Fabeta, 2013). 
ISTIGHNA, Vol. 3, No 1, Januari 2020 P-ISSN 1979-2824 E-ISSN 2655-8459

Homepage: http://e-journal.stit-islamic-village.ac.id/index.php/istighna

Burhanudin, Ari Prayoga, Irawan

Manajemen Peningkatan Mutu Pendidikan di Sekolah Islam

d. Informal control (pengendalian konsumen) adalah penilaian yang dilakukan masyarakat atau konsumen, baik langsung maupun tidak langsung, misalnya melalui media masa cetak atau elektronik.

\section{Perbaikan Mutu}

Pada pelaksanaan perbaikan mutu SMP Plus Al-Aqsha melakukan langkahlangkah perbaikan diantaranya dengan cara pengembangan infrastruktur, evaluasi atau penilaian kinerja, dan juga menerapkan program-program kerja yang di unggulkan sekolah.Dalam pengembangan infrastruktur sekolah mengelola dana sumbangan dari orang tua siswa karena sejak tahun 2010 sekolah tidak menerima dana sumbangan dari pemerintah. Pengelolaannya yaitu dengan cara memasukan infrastruktur pada rincian dana yang di keluarkan orang tua ketika ingin memasukan anaknya di SMP Plus Al-Aqsha, sehingga dengan demikian infrastruktur sekolah dapat di kelola dengan baik.

Langkah selanjutnya yang dilakukan dalam perbaikan mutu adalah evaluasi. Evaluasi ini biasanya dilakukan setiap akhir semester dan untuk tahun sekarang 2018 akan dilaksanakan sebelum idul fitri. Dalam pelaksanaannya evaluasi ini melibatkan semua unsur sekolah termasuk komite sekolah. Rapat evaluasi ini untuk mengidentifikasi kekurangan-kekurangan sekolah dan juga pencapaian sekolah dalam kurun waktu satu semester. SPI sebagai tim khusus yang di tunjuk kepala sekolah dalam melakukan pengawasan memaparkan semua data temuannya di lapangan pada saat pelaksanaan evaluasi.

Program yang di tawarkan SMP Plus Al-Aqsha merupakan langkah berikutnya dalam meningkatkan mutu pendidikan, program-program tersebut diantaranya ${ }^{14}$ :

a. Program jangka pendek

Program jangka pendek SMP Plus Al-Aqsha adalah program kerja yang harus dicapai dalam kurun waktu 1 s/d 15 tahun (1994-2009), sebagai upaya untuk membuat program kerja yang lebih kongkrit berdasarkan kondisi objektif yang ada yaitu:

1) Penentuan dan peningkatan peran para pengelola (pegawai struktural) SMP Plus Al-Aqsha;

2) Pemberdayaan dan pengembangan SDM para pengurus, guru dan karyawan.

14 Kepala Sekolah, Dokumen Program Rencana Kerja Sekolah SMP Plus Al-Aqsha (Sumedang, 2019). 
ISTIGHNA, Vol. 3, No 1, Januari 2020 P-ISSN 1979-2824 E-ISSN 2655-8459

Homepage: http://e-journal.stit-islamic-village.ac.id/index.php/istighna

Burhanudin, Ari Prayoga, Irawan

Manajemen Peningkatan Mutu Pendidikan di Sekolah Islam

3) Pengadaan, penataan dan pengembangan administrasi pengelolaan lembaga, pengelolaan sistem pembelajaran dan pendidikan, sarana dan prasarana untuk pendidikan, dan pembelajaran serta asrama dan lingkungan kampus Pondok Modern Al-Aqsha.

4) Pengelolaan dan peningkatan kegiatan-kegiatan ekstrakulikuler seperti kegiatan pramuka, kursus komputer, seni baca al-quran, kaligrafi dan olahraga.

5) Upaya kerjasama dengan pihak lain dalam rangka pembangunan ekonomi Pondok Modern Al-Aqsha.

6) Optimalisasi kualitas pendidikan dan pembelajaran di SMP Plus Al-Aqsha.

b. Program jangka menengah

Program jangka menengah SMP Plus Pondok Modern Al-Aqsha adalah program kerja yang harus dicapai dalam kurun waktu 15 s/d 30 tahun (2009-2024), sebagai upaya untuk membuat program kerja yang lebih kongkrit berdasarkan kemungkinan kemampuan yang ada, yaitu:

1) Optimalisasi peran pegawai Struktural SMP Plus Al-Aqsha agar lebih kreatif, inovatif dan berdedikasi tinggi.

2) Meningkatkan kualitas SDM para pengurus, guru, karyawan, dan para pembantu di SMP Plus Al-Aqsha.

3) Mewujudkan struktur kelembagaan yang dikelola dengan baik oleh para pengelola dan pengurus Pondok modern Al-Aqsha.

4) Merumuskan pengembangan jenjang pendidikan (ke SMA Plus), sarana dan prasarana pendidikan dan asrama, serta lingkungan kampus Pondok Modern Alaqsha.

5) Menyelenggarakan kegiatan ekstrakulikuler yang dapat dijadikan bekal bagi para peserta didik dalam kehidupan bermasyarakat.

6) Mewujudkan kerjasama dengan pihak lain dalam rangka mengembangkan pendidikan, pembelajaran, keterampilan dan perekonomian Pondok Modern AlAqsha.

7) Meningkatkan kualitas pendidikan dan pembelajaran di Pondok Modern AlAqsha.

c. Program jangka panjang

Program jangka panjang SMP Plus Pondok Modern Al-aqsha adalah program kerja yang harus dicapai dalam kurun waktu 30 s/d 50 tahun, sebagai upaya untuk 
ISTIGHNA, Vol. 3, No 1, Januari 2020 P-ISSN 1979-2824 E-ISSN 2655-8459

Homepage: http://e-journal.stit-islamic-village.ac.id/index.php/istighna

Burhanudin, Ari Prayoga, Irawan

Manajemen Peningkatan Mutu Pendidikan di Sekolah Islam

memberikan arah bagi pelaksanaan berbagai program di SMP Plus Pondok Modern Al-Aqsha secara umum, yaitu:

1) Meningkatkan mutu dan kualitas pendidikan dan pembelajaran di SMP Plus AlAqsha agar peserta didik berakhlak mulia, berbadan sehat, dan berpengetahuan.

2) Mengupayakan agar SMP Plus Al-Aqsha menjadi lembaga pendidikan yang mandiri, unggul dan dikenal di dalam negeri maupun diluar negeri.

3) Meningkatkan mutu dan kualitas sarana dan prasarana pendidikan yang representatif dan tepat guna bagi seluruh peserta didik.

4) Mendirikan jenjang pendidikan lain yang lebih tinggi (SMA atau perguruan tinggi) yang mampu memenuhi kebutuhan pasar.

5) Berperan aktif mengisi pembangunan Indonesia secara utuh.

Sejalan teori sallis tentang langkah-langkah perbaikan mutu meliputi; mengembangkan infrastruktur, mengidentifikasi area tertentu yang membutuhkan perbaikan, merancang kerjasama tim dan memfasilitasi tim ${ }^{15}$.

\section{Hasil Perbaikan Mutu}

Hasil perbaikan mutu di SMP Plus Al-Aqsha akan berdampak pada kegiatan pembelajaran, prestasi siswa dan pencapaian sekolah, kepuasan pelanggan, dan juga pemenuhan delapan standar pendidikan nasional.

a. Kegiatan Pembelajaran

Kegiatan pembelajaran di sekolah merupakan bagian terpenting dari hasil perbaikan mutu di sekolah, dengan adanya kegiatan tersebut keberlangsungan sekolah akan semakin terjamin serta mampu mendukung tercapainya tujuan sekolah sehingga inovasi dalam kegiatan pembelajaran ini menjadi sangat penting. SMP Plus Al-Aqsha dalam kegiatan belajar mengajar mengembangkan inovasi baik dari kurikulum yang digunakan ataupun mata pelajaran yang diterapkan.

Dalam kurikulum SMP Plus Al-Aqsha menggunakan dua kurikulum yaitu: kurikulum nasional dan juga Kurikulum Pondok Modern Gontor serta kurikulum Pesantren salaf. Dalam penerapannya di lapangan kedua kurikulum tersebut menjadi keunggulan dari sekolah karena dengan adanya kedua kurikulum tersebut siswa bukan hanya memperoleh pengetahuan secara umum juga memperoleh ilmu agama yang

${ }^{15}$ Edward Sallis, Total Quality Management In Educationa (Yogyakarta: IRCiSoD, 2012). 
ISTIGHNA, Vol. 3, No 1, Januari 2020 P-ISSN 1979-2824 E-ISSN 2655-8459

Homepage: http://e-journal.stit-islamic-village.ac.id/index.php/istighna

Burhanudin, Ari Prayoga, Irawan

Manajemen Peningkatan Mutu Pendidikan di Sekolah Islam

lebih luas. Perbandingan kedua kurikulum tersebut dalam penerapannya $60 \%$ untuk kurikulum nasional dan $40 \%$ untuk kurikulum gontor dan pesantren salaf ${ }^{16}$.

b. Prestasi dan Pencapaian Sekolah

Prestasi yang di raih oleh peserta didik SMP Plus Al-Aqsha secara keseluruhan sudah sangat banyak, pada awal tahun 2018 SMP Plus Al-Aqsha mengirimkan peserta didiknya pada perlombaan resmi yang diadakan pemerintah seperti O2SN salah satunya dalam bidang seni pupuh sunda dalam perlombaan tersebut peserta utusan dari SMP Plus Al-Aqsha mendapat penghargaan. Selain itu banyak perlombaan yang diikuti oleh siswa SMP Plus Al-Aqsha dalam tingkat kabupaten ataupun propinsi dan menjadi juara salah satunya juara matematika tingkat provinsi $1^{17}$.

Prestasi sekolah yang sudah diraih salah satunya akreditasi, SMP Plus AlAqsha terakreditasi A. Dengan akreditasi ini keberadaan sekolah diakui oleh pemerintah serta semua kegiatannya dapat dipantau oleh pemerintah. Penghargaan ini tidak terlepas dari komitmen sekolah dalam mengimplementasikan aturan dan regulasi. Penghargaan selanjutnya yang diraih oleh sekolah adalah kepercayaan dari masyarakat terbukti dengan bertambahnya jumlah pendaftar ke SMP Plus Al-Aqsha yang mencapai 400 orang pada gelombang pertama di tahun ajaran 2017/2018.

c. Kepuasan pelanggan

Tolak ukur dalam menilai kepuasan pelanggan atau masyarakat terhadap keberadaan SMP Plus Al-Aqsha dilihat dari kepuasan siswa sebagai subjek dari pendidikan di SMP Plus Al-Aqsha. Menurut Siti Aisyah salah satu siswi kelas 8 SMP Plus Al-Aqsha, program yang ada di sekolah seperti pembiasan berbicara bahasa Inggris dan Arab, yang kedua program one day one juz, dan juga membaca al-Quran bersama setiap malam jumat. Ketiga program sangat diminati peserta didik untuk pengembangan individu.

d. Pemenuhan Delapan Standar Pendidikan Nasional

${ }^{16}$ Kepala Sekolah Bidang Kurikulum, Dokumen 1 Sekolah Menengah Pertama Plus AlAqsha Sumedang (Sumedang, 2019).

${ }^{17}$ Kepala Sekolah Bidang Kesiswaan, LC.5.2.WK.W.PSPS Dokumen Prestasi Siswa SMP Plus Al-Aqsha (Sumedang, 2019). 
ISTIGHNA, Vol. 3, No 1, Januari 2020 P-ISSN 1979-2824 E-ISSN 2655-8459

Homepage: http://e-journal.stit-islamic-village.ac.id/index.php/istighna

Burhanudin, Ari Prayoga, Irawan

Manajemen Peningkatan Mutu Pendidikan di Sekolah Islam

Dalam pemenuhan delapan standar pendidikan nasional langkah yang dilakukan sekolah yaitu bekerja sama dengan pengawas pendidikan untuk melakukan pelatihan. Pelatihan RSBS yang diadakan setiap hari Jumat, yang di dalamnya terdapat pelatihan administarsi guru dan juga cara guru mengajar di dalam kelas. Hal ini dilakukan untuk menunjang standar proses di SMP Plus Al-Aqsha.

\section{KESIMPULAN}

Berdasarkan hasil penelitian dapat disimpulkan bahwa; pertama, perencanaan peningkatan mutu di SMP Plus Al-Aqsha Sumedang dilakukan oleh semua unsur pimpinan seperti kepala sekolah dan ketua yayasan, meliputi langkah-langkah analsis kebutuhan pasar, perumusan visi, misi dan tujuan sekolah serata penentuan program jangka pendek, menengah dan panjang; kedua, pengendalian peningkatan mutu di SMP Plus Al-Aqsha dilakukan oleh kepala sekolah, meliputi langkah-langkah merancang struktur kerja, dan pengawasan dengan membentuk SPI (Satuan Pengawas Internal); ketiga, perbaikan peningkatan mutu di SMP Plus Al-Aqsha Sumedang meliputi langkah-langkah pengembangan infrastruktur, identifikasi area tertentu yang membutuhkan perbaikan, serta melakukan evaluasi yang dilakukan setiap akhir semester; keempat, hasil dari peningkatan mutu di SMP Plus Al-Aqsha berdampak pada kegiatan belajar mengajar, prestasi siswa dan pencapaian sekolah, kepuasan pelanggan dan juga pemenuhan delapan standar pendidikan nasional.

\section{REFERENSI}

Badrudin, Dasar-Dasar Manajemen (Bandung: Al-Fabeta, 2013)

Buckley, Philip, and Irawan Irawan, 'The Scientific Paradigm of Islamic Education Management: Phenomenology Perspective', Jurnal Pendidikan Islam, 2 (2015), 129 <https://doi.org/10.15575/jpi.v2i1.701>

Kepala Sekolah, CL.2.KS.W.PM. Wawancara Terstruktur Data Kelembagaan Sekolah (Sumedang, 2019)

_- Dokumen Program Rencana Kerja Sekolah SMP Plus Al-Aqsha (Sumedang, 2019)

Kepala Sekolah Bidang Kesiswaan, LC.5.2.WK.W.PSPS Dokumen Prestasi Siswa SMP Plus Al-Aqsha (Sumedang, 2019)

Kepala Sekolah Bidang Kurikulum, Dokumen 1 Sekolah Menengah Pertama Plus AlAqsha Sumedang (Sumedang, 2019) 
ISTIGHNA, Vol. 3, No 1, Januari 2020 P-ISSN 1979-2824 E-ISSN 2655-8459

Homepage: http://e-journal.stit-islamic-village.ac.id/index.php/istighna

Burhanudin, Ari Prayoga, Irawan

Manajemen Peningkatan Mutu Pendidikan di Sekolah Islam

Lexy J. Moleong, Metode Penelitian Kualitatif (Bandung: Remaja Rosdakarya, 2004)

Miles, M. B., and A. M. Huberman, Qualitative Data Analysis, Second Edi (London: SAGE Publications, Inc., 1994)

Prayoga, Ari, Rismaya Muharomah, and Sutarti Sutarti, 'Implementasi Kepemimpinan Transformatif Kepala Madrasah Aliyah Ma'arif Cilageni Kadungora', Attaqwa: Jurnal Ilmu Pendidikan Islam, $15 \quad$ (2019), 33-44 <https://doi.org/10.5281/zenodo.3375534>

Prayoga, Ari, Azhar Widad, Elin Marliana, Ima Mukarromah, and Uus Ruswandi, 'Implementasi Penjaminan Mutu Madrasah', Muróbbî: Jurnal Ilmu Pendidikan, 3 (2019), 70-84 <http://jurnal.iaibafa.ac.id/index.php/murobbi /article/view/183>

Sagala, Syaiful, Konsep Dan Makna Belajaran Untuk Membantu Memecahkan Problematika Belajar Dan Mengajar, II (Bandung: Alfabeta, 2010)

Sallis, Edward, Total Quality Management In Educationa (Yogyakarta: IRCiSoD, 2012)

Sugiyono, Metode Penelitian Kuantitatif, Kualitatif Dan R\&D, 24th edn (Bandung: Alfabeta, 2016)

Suharsaputra, Uhar, Administrasi Pendidikan (Bandung: PT. Rafika Aditama, 2014)

Syaodih, Nana, Pengendalian Mutu Pendidikan Sekolah Menengah, I (Bandung: Refika Aditama, 2006)

UU SISDIKNAS RI., Undang-Undang Republik Indonesia Nomor 20 Tahun 2003 Tentang Sistem Pendidikan Nasional (Jakarta, 2003) 